\title{
Lipocalin 2 Level Predicts Prognostic Outcome in Patients with Colorectal Cancer Undergoing Surgical Intervention
}

Chia-Lo Chang ${ }^{1}$, Yung-Lung Chen ${ }^{2}$, Yen-Ta Chen ${ }^{3}$, Steve Leu ${ }^{4}$, Li-Teh Chang ${ }^{5}$, Chang-Han Chen ${ }^{4}$, Chien-Chang Lư ${ }^{1}$, Wang-Hseng Hu${ }^{1}$, KoChao Lee ${ }^{1}$, Kai-Lung Tsai ${ }^{1}$, Hsueh-Wen Chang ${ }^{6}$, Hong-Hwa Chen ${ }^{1 *}$ and Hon-Kan Yip ${ }^{2,4,7 *}$

${ }^{1}$ Division of Colorectal Surgery, Department of Surgery, Kaohsiung Chang Gung Memorial Hospital and Chang Gung University College of Medicine, Kaohsiung, Taiwan ${ }^{2}$ Division of Cardiology, Department of Internal Medicine, Kaohsiung Chang Gung Memorial Hospital and Chang Gung University College of Medicine, Kaohsiung, Taiwan ${ }^{3}$ Division of Urology, Department of Surgery, Kaohsiung Chang Gung Memorial Hospital and Chang Gung University College of Medicine, Kaohsiung, Taiwan ${ }^{4}$ Center for Translational Research in Biomedical Sciences, Kaohsiung Chang Gung Memorial Hospital and Chang Gung University College of Medicine, Kaohsiung, Taiwan

${ }^{5}$ Basic Science, Nursing Department, Meiho University, Pingtung, Taiwan

${ }^{6}$ Department of Biological Sciences, National Sun Yat-Sen University, Kaohsiung, Taiwan

${ }^{7}$ Center of Shock Wave Medicine and Tissue Engineering, Taiwan

\begin{abstract}
This study examined the predictive role of circulating lipocalin 2 in long-term prognostic outcome of Colorectal Cancer (CRC) patients with surgical intervention.

204 CRC patients with surgical intervention between April 2009 and May 2011 were prospectively enrolled. Circulating lipocalin 2 levels in CRC patients before surgery and healthy-control subjects were measured using ELISA. Patients were categorized into different CRC clinical stage (I to IV) based on pathological findings. Mean follow-up time was $21.2 \pm 3.5$ months. Patients were categorized into group 1 ( $n=67$ ), lipocalin 2 levels $<116.7 \mathrm{ng} /$ $\mathrm{ml}$; and group $2(\mathrm{n}=137)$, lipocalin 2 levels $\geq 116.7 \mathrm{ng} / \mathrm{ml}$ by ROC curve analysis. CRC patients had higher circulating levels of lipocalin 2 than healthy subjects $(P<0.0001)$. Occurrence of new metastases after surgery, primary (any cause of death or new metastasis) and secondary (CRC-related death and new metastasis) combined endpoint were higher in group 1 than group 2 (all $P<0.03$ ). Lower lipocalin 2 levels and CRC stage IV was independently predictive of primary and secondary combined endpoint (all $P<0.001)$ during long-term follow-up. In conclusion, circulating lipocalin 2 level may be a useful biomarker for risk stratification of CRC patients during long-term follow-up.
\end{abstract}

Keywords: Lipocalin 2; Colorectal Cancer (CRC); Prognostic outcome

\section{Introduction}

Colorectal Cancer (CRC) is the fourth leading cause of cancer death in Western countries, and it is the most common cause among gastrointestinal tract malignancies [1-3]. The long-term prognostic outcome of CRC is usually favorable if there is early diagnosis and treatment $[4,5]$. On the other hand CRC cases diagnosed at an advanced stage result in a high mortality rate because of the relatively asymptomatic nature of early-stage disease and lack of adequate screening tests $[1,6,7]$. Adequate early detection screening for CRC has been reported to greatly improve patient survival (occult blood or colonoscope) $[8,9]$.

Traditionally, early detection of CRC has largely focused on Carcinoembryonic Antigen (CEA) as a serum marker. However, the usefulness of CEA as a biomarker for early diagnosis is limited by the fact that CEA exhibits lower sensitivity and specificity in early-stage disease $[10,11]$. The limitations of CEA in the early detection of CRC mean that there is a need to evaluate other potential biomarkers to complement CEA to enhance diagnostic sensitivity and specificity and improve predictive prognostic outcome in CRC in daily clinical practice.

Lipocalin 2, (also known as matrix metalloproteinase 9) is a 25 $\mathrm{kDa}$ glycoprotein that was initially purified from neutrophil granules $[12,13]$. This small protein molecule was first purified from granules of human neutrophils, and thus is also named Neutrophil GelatinaseAssociated Lipocalin (NGAL) [12,13]. A variety of functions have been attributed to lipocalin 2, including transport of iron [14], induction of apoptosis in cytokine-dependent neutrophils [15], suppression of bacterial growth through the binding of bacterial catecholatetype ferric siderophores (i.e., resulting in iron sequestration) $[16,17]$, and modulation of inflammatory responses [18,19]. Accumulating evidence suggests that lipocalin 2 plays an important role in innate immune response [15].

In addition, experimental data have shown that lipocalin 2 plays an important role in regulating cell growth since its expression is highly upregulated in a variety of proliferative cells such as cancer cells $[20,21]$ Increased lipocalin 2 expression has been reported in various cancers including ovarian, pancreatic, lung and breast cancers, indicating there is a strong association between this biomarker and the malignance of cancer cells and metastasis [20-23]. Surprisingly, a link between circulating level of this biomarker and metastasis and prognostic outcome of CRC has not been reported. Particularly surprising is that even the results of in vitro studies appear to be inconsistent; one study showed that overexpression of lipocalin 2 aggravated metastatic colon cancer cells [24], while another showed an opposite pattern [20]. In this

*Corresponding authors: Hong-Hwa Chen, Division of Colorectal Surgery Department of Surgery, Kaohsiung Chang Gung Memorial Hospital and Chang Gung University College of Medicine, Kaohsiung, Taiwan, Tel: 886-7-7317123 ext: 2363 or 8300; E-mail: huangwentsung@mac.com

Hon-Kan Yip, Division of Cardiology, Department of Internal Medicine, Kaohsiung Chang Gung Memorial Hospital and Chang Gung University College of Medicine, Kaohsiung, Taiwan, E-mail: han.gung@msa.hinet.net

Received December 11, 2013; Accepted Januauary 15, 2014; Published Januauary 21, 2014

Citation: Chang CL, Chen YL, Chen YT, Leu S, Chang LT, et al. (2014) Lipocalin 2 Level Predicts Prognostic Outcome in Patients with Colorectal Cancer Undergoing Surgical Intervention. J Mol Biomark Diagn 5: 162. doi:10.4172/2155-9929.1000162

Copyright: $\odot 2014$ Chang CL, et al. This is an open-access article distributed under the terms of the Creative Commons Attribution License, which permits unrestricted use, distribution, and reproduction in any medium, provided the original author and source are credited 
Citation: Chang CL, Chen YL, Chen YT, Leu S, Chang LT, et al. (2014) Lipocalin 2 Level Predicts Prognostic Outcome in Patients with Colorectal Cancer Undergoing Surgical Intervention. J Mol Biomark Diagn 5: 162. doi:10.4172/2155-9929.1000162

Page 2 of 7

study we investigated whether increased circulating level of lipocalin 2 may be a useful biomarker by which to predict metastasis and clinical outcome of CRC after surgical intervention.

\section{Methods}

\section{Patient population, data collection and therapeutic strategy}

All patients who presented with CRC at Kaohsiung Chang Gung Memorial Hospital were evaluated, and their eligibility for surgical intervention was considered. CRC was categorized into stage I, II, III and IV according to pathological findings and the criteria of JN VII [25].

Detailed in-hospital and follow-up data, including age, gender, colonscopic findings, computer tomography, ultrasonographic scans and other image findings, and histological, pathological and surgical findings were collected prospectively and entered into a computer database. Additionally, for the purpose of the study, all patients who experienced CRC undergoing surgical intervention were eligibly considered for collections of pathological specimens. The resection of the cancer tissue and blood sampling of patients after informed consent were obtained from each patient. These pathological specimens from CRC and blood sample were stored in tissue bank of our hospital. The whole process was monitored by the committee of tissue bank. Each researcher who is interested in the CRC must fill out the application form to apply for the use of specimen or blood sample. The authority for utilizing the specimen belonged to the committee of tissue bank.

For the purpose of the present study, we were granted permission of utilizing specimens for research by the committee of the tissue bank. Two-hundred and four consecutive patients of all ages who were diagnosed with CRC for the first time and underwent surgical intervention between April 2009 and May 2011 were prospectively enrolled into the study (stage I, $n=48$; stage II, $n=69$; stage III, $n=49$; stage IV, $\mathrm{n}=38$ ) (Table 1).

In addition to surgical intervention adjunct therapeutic strategies

\begin{tabular}{|c|c|c|c|}
\hline Variables & $\begin{array}{c}\text { Colorectal cancer } \\
(\mathrm{n}=204)\end{array}$ & $\begin{array}{c}\text { Healthy control } \\
(\mathrm{n}=10)\end{array}$ & P value \\
\hline Age $(\mathrm{yr})$ & $64.4 \pm 11.8$ & $65.4 \pm 3.1$ & 0.447 \\
\hline Male gender & $54.4 \%(111)$ & $60.0 \%(6)$ & 1.000 \\
\hline WBC count $\left(\times 10^{3} / \mu \mathrm{l}\right)$ & $7.4 \pm 2.5$ & $6.0 \pm 2.0$ & 0.063 \\
\hline Hemoglobin $(\mathrm{g} / \mathrm{dl})$ & $12.2 \pm 2.4$ & $14.2 \pm 2.0$ & 0.011 \\
\hline CEA $(\mathrm{ng} / \mathrm{ml})$ & $122.8 \pm 626.5$ & $3.3 \pm 2.7$ & 0.008 \\
\hline Albumin $(\mathrm{g} / \mathrm{dl})$ & $4.0 \pm 1.4$ & $4.3 \pm 0.2$ & 0.483 \\
\hline BUN $(\mathrm{mg} / \mathrm{dl})$ & $14.0 \pm 12.9$ & $14.0 \pm 5.2$ & 0.993 \\
\hline Creatinine $(\mathrm{mg} / \mathrm{dl})$ & $1.0 \pm 1.3$ & $0.8 \pm 0.2$ & 0.484 \\
\hline Total bilirubin $(\mathrm{mmol} / \mathrm{L})$ & $0.7 \pm 0.3$ & $1.0 \pm 0.5$ & 0.124 \\
\hline Phosphate $(\mathrm{mg} / \mathrm{ml})$ & $3.5 \pm 0.9$ & $3.4 \pm 0.5$ & 0.664 \\
\hline Alk-P $(\mathrm{U} / \mathrm{L})$ & $79.5 \pm 61.3$ & $59.6 \pm 21.3$ & 0.332 \\
\hline AST $(\mathrm{IU} / \mathrm{L})$ & $28.3 \pm 19.5$ & $27.9 \pm 6.6$ & 0.943 \\
\hline Lipocalin $2(\mathrm{ng} / \mathrm{ml})$ & $193.3 \pm 135.4$ & $36.5 \pm 16.1$ & $<0.0001$ \\
\hline Stages of colorectal cancer & & & \\
\hline I & $23.5 \%(48)$ & - & \\
\hline II & $33.8 \%(69)$ & - & \\
\hline III & $24.0 \%(49)$ & - & \\
\hline IV & $18.6 \%(38)$ & - & \\
\hline
\end{tabular}

Data are expressed as mean \pm SD or $\%(n)$.

Alk-P: Alkaline Phosphatase; AST: Aspartate Aminotransferase; BUN: Blood Urea Nitrogen; CEA: Carcinoembryonic Antigen; WBC: White Blood Cell.

Table 1: Baseline Characteristics, Laboratory Findings and Serum Level of Lipocalin 2 in Study Patients and Control Subjects. for CRC patients were as follows: 1) patients with stage I CRC did not receive any adjunct therapy in addition to surgical intervention; 2) patients with stage II or III colon cancer routinely received chemotherapy; 3) patients with stage II rectal cancer received radiotherapy; 4) patients with stage III rectal cancer received combined chemotherapy and radiotherapy; 5) patients with stage IV CRC received combined chemotherapy and target therapy.

Ten age- and gender-matched healthy controls were also studied. Informed consent was obtained from each study subject. The whole study protocol was approved by the Institutional Review Committee on Human Research of the Institute of Kaohsiung Chang Gung Memorial Hospital (the IRA number: 100-1024B).

To circumvent other potential influences on measurement of circulating level of lipocalin 2, patients with one or more of the following were excluded: recent surgery or trauma during the preceding 2 months, an inoperable condition, refused surgical intervention with other palliative treatment, diagnosed as having recurrent CRC during the enrollment period, other co-existent malignances, history of febrile disorders, acute or chronic inflammatory disease other than CRC during the study period, and history of autoimmune diseases with or without immunosuppressive therapy.

\section{Blood sampling for ELISA, biochemistry and white blood cell count study}

Blood samples were obtained once prior to CRC surgery from study subjects and once from the ten healthy control subjects who participated in a health screening program in the Health Clinic of Kaohsiung Chang Gung Memorial Hospital.

After centrifugation, the aliquot of the samples was stored at $-80^{\circ} \mathrm{C}$ before assay for lipocalin 2 level. White Blood Cell (WBC) counts, biochemistry, CEA measurements and electrolyte levels were performed using standard laboratory methods.

Serum lipocalin 2 level was measured in duplicate with a commercially available ELISA kit (R\&D Systems). The intra-observer variability of the measurements of lipocalin 2 levels was also assessed and the mean intra-assay coefficients of variance were all $<4.1 \%$.

\section{Definitions of endpoints and occurrence of new metastasis during long-term follow-up}

The primary combined endpoint was defined as any cause of death or metastasis during long-term follow-up. The secondary combined endpoint was defined as death caused by CRC or metastasis during long-term follow-up. The occurrence of new metastasis was defined as distal organ metastasis observed after post-surgical long-term followup.

\section{Statistical analysis}

Data were expressed as means $\pm \mathrm{SD}$. Continuous variables were analyzed using the independent $\mathrm{t}$-test, and categorical variables were analyzed using the Chi-square test. Areas under the Receiver Operator Characteristic (ROC) curve were used to determine the sensitivity and specificity of lipocalin 2 and CEA in predicting long-term clinical outcome (i.e., freedom from death or cancer metastasis) in patients with CRC. The correlation between circulating levels of lipocalin 2 and the clinical stages of CRC were analyzed with Pearson product-moment correlation coefficient. Baseline variables were used for univariable Cox regression analysis. All significant factors revealed by univariable Cox regression analysis were further examined by multivariable stepwise 
Citation: Chang CL, Chen YL, Chen YT, Leu S, Chang LT, et al. (2014) Lipocalin 2 Level Predicts Prognostic Outcome in Patients with Colorectal Cancer Undergoing Surgical Intervention. J Mol Biomark Diagn 5: 162. doi:10.4172/2155-9929.1000162

Page 3 of 7

Cox regression analysis. Multivariable stepwise Cox regression analysis was used to assess the independent predictors of long-term clinical outcomes. Statistical analysis was performed using SPSS statistical software (SPSS for Windows, version 13; SPSS, IL). A P value of $<0.05$ was considered statistically significant.

\section{Results}

Baseline characteristics, laboratory results and serum lipocalin 2 level in study patients and control subjects

Age and gender did not differ between study subjects and healthy control subjects. Additionally, WBC count, albumin level, and parameters of renal function and liver function indices were similar between study patients and healthy control subjects. However, hemoglobin level was significantly lower in study subjects than in healthy control subjects. Conversely, the serum level of CEA and lipocalin 2 were remarkably higher in study patients than in control subjects. The incidence of CRC was highest at stage II, followed by stage I and II, and lowest in stage IV in the current study (Table 1).

Comparison of baseline variables, laboratory findings, clinical presentation, and long-term outcomes in patients with higher and lower levels of lipocalin 2

ROC curve analysis (Figure 1) revealed that circulating level of lipocalin $2 \geq 116.7(\mathrm{ng} / \mathrm{ml})$ was the most powerful predictor of favorable long-term clinical outcome (i.e., freedom from death or cancer metastasis) in the current study with a sensitivity of $73.0 \%$ and a specificity of $60.0 \%$. The positive and negative predictive values were $20.3 \%$ and $94.1 \%$, respectively. Accordingly, patients with levels of lipocalin $2<116.7(\mathrm{ng} / \mathrm{ml})$ were categorized into the patient group with lower levels of lipocalin 2 (group 1), and patients with levels of lipocalin $\geq 116.7(\mathrm{ng} / \mathrm{ml})$ were assigned into the group with higher levels of lipocalin 2 (group 2) (Table 2).

Age was not no significantly different between group 1 and group 2. However, there were significantly less men than women in group 1

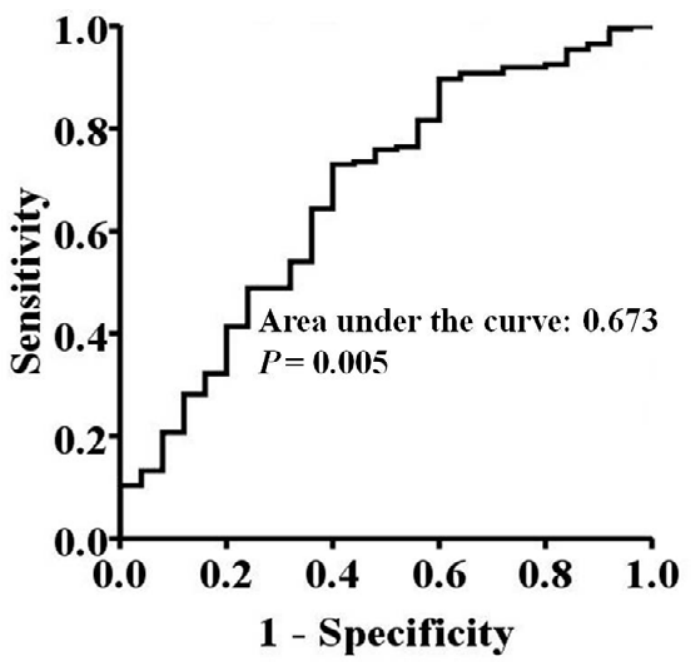

Figure 1: Receiver operating characteristic (ROC) plot: Receiver Operating Characteristic (ROC) plot of circulating level of lipocalin $2 \geq 116.7(\mathrm{ng} / \mathrm{ml})$ and freedom from death or cancer metastasis. The area under the curve was 0.673 . When the cut-off value of lipocalin $2 \geq 116.7(\mathrm{ng} / \mathrm{ml})$, the sensitivity and specificity were $73.0 \%$ and $60.0 \%$, respectively for predicting freedom from long-term death or cancer metastasis.

\begin{tabular}{|c|c|c|c|}
\hline Variables & Group $1(n=67) \ddagger$ & Group $2(n=137) \ddagger$ & $P$ value \\
\hline Age (yr) & $67.6 \pm 10.1$ & $64.8 \pm 12.6$ & 0.465 \\
\hline Male gender & $43.3 \%(29)$ & $59.9 \%(82)$ & 0.026 \\
\hline WBC count $\left(\times 10^{3} / \mu \mathrm{l}\right)$ & $6.9 \pm 2.4$ & $7.7 \pm 2.5$ & 0.037 \\
\hline Hemoglobin (g/dl) & $12.2 \pm 2.4$ & $12.3 \pm 2.4$ & 0.794 \\
\hline CEA (ng/ml) & $90.2 \pm 515.1$ & $138.8 \pm 675.9$ & 0.607 \\
\hline Albumin (g/dl) & $4.3 \pm 2.2$ & $3.9 \pm 0.6$ & 0.027 \\
\hline $\mathrm{BUN}(\mathrm{mg} / \mathrm{dl})$ & $13.3 \pm 12.5$ & $14.4 \pm 13.2$ & 0.557 \\
\hline Creatinine (mg/dl) & $0.9 \pm 0.9$ & $1.1 \pm 1.4$ & 0.229 \\
\hline Total bilirubin (mmol/L) & $0.7 \pm 0.3$ & $0.7 \pm 0.3$ & 0.339 \\
\hline Phosphate (mg/ml) & $3.5 \pm 0.4$ & $3.5 \pm 1.0$ & 0.972 \\
\hline Alk-P (U/L) & $71.6 \pm 28.7$ & $83.5 \pm 72.1$ & 0.214 \\
\hline AST (IU/L) & $27.5 \pm 13.5$ & $28.8 \pm 21.9$ & 0.664 \\
\hline Lipocalin 2 (ng/ml) & $75.34 \pm 29.2$ & $246.7 \pm 130.8$ & $<0.001$ \\
\hline Stages of colorectal cancer & & & 0.032 \\
\hline I & $22.4 \%(15)$ & $24.1 \%(33)$ & \\
\hline II & $23.9 \%(16)$ & $38.7 \%(53)$ & \\
\hline III & $35.8 \%(24)$ & $18.2 \%(25)$ & \\
\hline IV & $17.9 \%(12)$ & $19.0 \%(26)$ & \\
\hline Duration of follow-up (days) & $455.9 \pm 187.0$ & $539.8 \pm 201.3$ & 0.005 \\
\hline Mortality of any cause & $14.9 \%(10)$ & $11.7 \%(16)$ & 0.514 \\
\hline Mortality due to CRC & $10.4 \%(7)$ & $5.1 \%(7)$ & 0.236 \\
\hline Occurrence of new metastasis & $16.4 \%(9)$ & $3.3 \%(4)$ & 0.004 \\
\hline Primary combined endpoint* & $25.4 \%(17)$ & $13.1 \%(18)$ & 0.029 \\
\hline Secondary combined endpoint $†$ & $22.4 \%(15)$ & $7.3 \%(10)$ & 0.002 \\
\hline
\end{tabular}

Data are expressed as mean \pm SDor $\%(n)$.

Alk-P = Alkaline Phosphatase; AST = Aspartate Aminotransferase; $B U N=$ Blood Urea Nitrogen; CEA = Carcinoembryonic Antigen; $\mathrm{CRC}=$ Colorectal Cancer; WBC $=$ White Blood Cell.

* Defined as any cause of death or occurrence of new metastasis during longterm follow-up.

† Defined as death caused by CRC or metastasis during long-term follow-up. $\ddagger$ Group 1: defined as lower lipocalin $2(<116.7 \mathrm{ng} / \mathrm{ml})$ level; group 2: defined as higher lipocalin 2( $\geq 116.7 \mathrm{ng} / \mathrm{ml})$ level.

Table 2: Comparison of Baseline Characteristics, Laboratory Findings and Clinical Outcomes between Higher Lipocalin 2 and lower Lipocalin 2 Study Patients.

than in group 2. The laboratory findings showed that hemoglobin and CEA levels, and renal and liver function were similar in group 1 and group 2. However, albumin level was higher and WBC count was lower in group 1 than in group 2. Additionally, circulating level of lipocalin 2 was substantially lower in group 1 than in group 2 .

The incidence of CRC stage was found to be significantly different between group 1 and group 2 . This result was mainly due to the fact that the incidences of stage II CRC was notably lower whereas the incidence of stage III CRC was remarkably higher in group 1 than in group 2 (Table 2).

The duration of long-term follow up after discharge from hospitalization was significantly shorter in group 1 than in group 2 . This was mainly due to the relatively higher incidence of long-term CRC-related mortality in group 1 than in group 2 but this difference did not reach statistical significance (Table 2).

The incidence of new onset of CRC metastasis was significantly higher in group 1 than in group 2. Additionally, the primary and secondary combined endpoints during long-term follow up were significantly higher in group 1 than in group 2 .

Correlation between circulating level of lipocalin 2 and the stages of CRC at time of blood sampling

To determine whether there was a correlation between serum level 
Citation: Chang CL, Chen YL, Chen YT, Leu S, Chang LT, et al. (2014) Lipocalin 2 Level Predicts Prognostic Outcome in Patients with Colorectal Cancer Undergoing Surgical Intervention. J Mol Biomark Diagn 5: 162. doi:10.4172/2155-9929.1000162

Page 4 of 7

of lipocalin 2 and the clinical stages of CRC, Spearman rank correlation analysis was performed. Unexpectedly, the result of the analysis revealed no significant correlation between the level of lipocalin 2 and individual stage of CRC (Figure 2A). Further analysis also showed no correlation between level of lipocalin 2 and combined stages (I, II, III) of CRC and stage IV of CRC (Figure 2B).

Univariable and multivariable stepwise Cox regression analysis of predictors for primary combined endpoint during long-term follow-up

The results of univariate Cox regression analysis of the enrollment variables (Table 2) for prediction of primary combined endpoint during long-term follow-up are shown in (Tables 3 and 4). The most significant factors among these variables were WBC count, CEA level (an increase in each $10 \mathrm{ng} / \mathrm{ml}$ of CEA), and CRC stage IV. Additionally, lower levels of lipocalin 2, hemoglobin and albumin were also significantly related to combined endpoint of long-term follow-up.

Multivariable stepwise Cox regression analysis revealed that lower level lipocalin 2, WBC count and CRC stage IV were the most significant independent predictors for primary combined endpoint during long-term follow-up. Moreover, CEA level (an increase in each $10 \mathrm{ng} / \mathrm{ml}$ of CEA) was also significantly and independently predictive of primary combined endpoint in long-term follow-up.

(A)

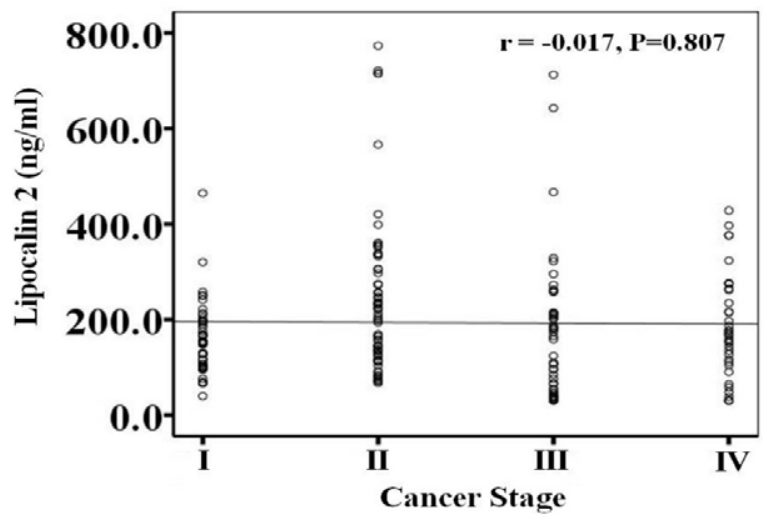

(B)

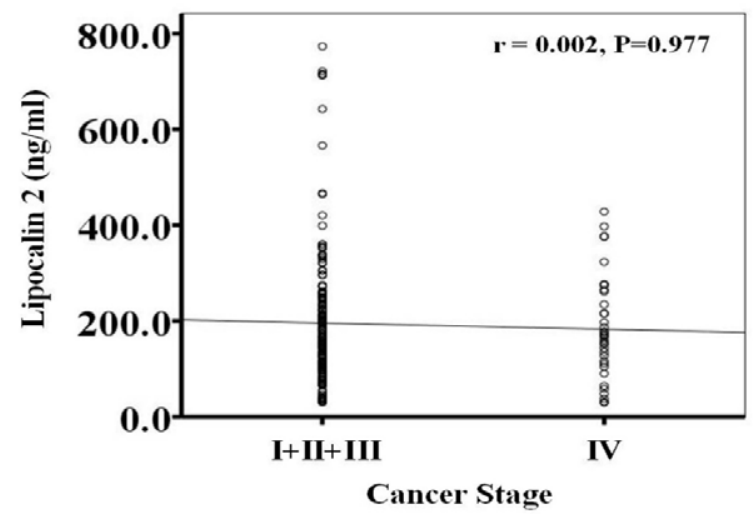

Figure 2: Linear regression analysis : $(A)$ Linear regression analysis for the correlation between lipocalin 2 and individual cancer stage $(p=0.807 ; r=$ -0.017). (B) Linear regression analysis for the correlation of lipocalin 2 to early cancer (stage I, II ,III ) or advanced cancer stage $(p=0.977 ; r=0.002)$.

\begin{tabular}{|c|c|c|}
\hline Variables & Hazard ratio $(95 \% \mathrm{Cl})$ & $\mathrm{P}$ value \\
\hline White blood cell count $\left(\times 10^{3} / \mathrm{\mu l}\right)^{*}$ & $1.200(1.083-1.328)$ & $<0.001$ \\
\hline Hemoglobin $(\mathrm{g} / \mathrm{dl})^{*}$ & $0.832(0.735-0.941)$ & 0.003 \\
\hline CEA $(\times 10 \mathrm{ng} / \mathrm{ml})^{*} \dagger$ & $1.001(1.005-1.0011)$ & $<0.001$ \\
\hline CEA $(>3.27 \mathrm{ng} / \mathrm{ml})$ & $3.099(1.509-6.367)$ & 0.002 \\
\hline Cancer stage $(\mathrm{I}+\mathrm{II}+\mathrm{III}$ vs. IV) & $7.318(3.701-14.472)$ & $<0.001$ \\
\hline Lower level of lipocalin $2[<116.7(\mathrm{ng} / \mathrm{ml})]$ & $2.950(1.475-5.899)$ & 0.002 \\
\hline Albumin $(\mathrm{g} / \mathrm{dl})^{*}$ & $0.463(0.287-0.747)$ & 0.002 \\
\hline
\end{tabular}

*Value was used as continuity.

† Indicated increased each 1.001 Hazard ratio with respect to increase in $10 \mathrm{ng} /$ $\mathrm{ml}$ of CEA.

$\ddagger$ Primary combined endpoint was defined as any cause of death or occurrence of new onset of metastasis during long-term follow-up.

$\mathrm{Cl}$ : Confidence Interval; CEA: Carcinoembryonic Antigen; CRC: Colorectal Cancer.

Table 3: Univariable Cox Regression Analysis of Predictors for Primary Combined Endpoint During Long-term Follow-upł.

\begin{tabular}{|c|c|c|}
\hline Variables & Hazard ratio $(95 \% \mathrm{Cl})$ & $\mathrm{P}$ value \\
\hline WBC $\left(\times 10^{3} / \mu \mathrm{l}\right)^{*}$ & $1.327(1.170-1.506)$ & $<0.001$ \\
\hline CRC stage $(\mathrm{I}+\mathrm{II}+\mathrm{III}$ vs. IV) & $8.788(3.928-19.662)$ & $<0.001$ \\
\hline Lower level of lipocalin $2[<116.7(\mathrm{ng} / \mathrm{ml})]$ & $6.854(2.928-16.047)$ & $<0.001$ \\
\hline CEA $(\times 10 \mathrm{ng} / \mathrm{ml})^{*} \dagger$ & $1.004(1.0005-1.0083)$ & 0.028 \\
\hline
\end{tabular}

*Value was used as continuity.

† Indicated increased each 1.001 Hazard ratio with respect to increase in $10 \mathrm{ng} /$ $\mathrm{ml}$ of CEA.

‡Primary combined endpoint was defined as any cause of death or occurrence of new onset of metastasis during long-term follow-up.

$\mathrm{Cl}$ : Confidence Interval; CEA: Carcinoembryonic Antigen; CRC: Colorectal Cancer.

Table 4: Multivariable Stepwise Cox Regression Analysis of Predictors for Primary Combined Endpoint During Long-term Follow-upł.

In the current study, subgroup analysis was also conducted to elucidate which CEA level was the cut-off value for significant prediction of unfavorable long-term clinical outcome (i.e., death from any cause or cancer metastasis), ROC curve analysis was performed and the results revealed that the level of CEA $\geq 3.27(\mathrm{ng} / \mathrm{ml})$ was the most powerful predictor with a sensitivity of $68.6 \%$ and a specificity of $63.6 \%$, respectively [AUC: 0.694 (0.590-0.798), $P<0.001$ ]. Furthermore, reanalysis of variables in Table 4 by using a combination of cut-off level of CEA (i.e., $\geq 3.27 \mathrm{ng} / \mathrm{ml}$ ) and higher lipocalin 2 level was superior to either one alone for predicting primary combined endpoint [6.400 (2.929-13.982), $P<0.0001]$.

Univariable and multivariable stepwise Cox regression analysis of predictors for secondary combined endpoint during long-term follow-up

The results of univariate Cox regression analysis of the enrollment variables (Table 2) for prediction of secondary combined endpoint during long-term follow-up are shown in Tables 5 and 6 . The most powerful predictors among these variables were lower levels of lipocalin 2 and CRC stage IV. In addition, the CEA level was also significantly associated with combined endpoint during long-term follow-up.

Multivariable stepwise Cox regression analysis showed that only the lower level lipocalin 2 and CRC stage IV were significantly and independently predictive of primary combined endpoint in long-term follow-up.

Kaplan Meyer analysis showed that freedom from combined primary endpoint and secondary combined endpoint were remarkably higher in higher level of lipocalin $2(\geq 116.7 \mathrm{ng} / \mathrm{ml})$ patients in 
Citation: Chang CL, Chen YL, Chen YT, Leu S, Chang LT, et al. (2014) Lipocalin 2 Level Predicts Prognostic Outcome in Patients with Colorectal Cancer Undergoing Surgical Intervention. J Mol Biomark Diagn 5: 162. doi:10.4172/2155-9929.1000162

Page 5 of 7

\begin{tabular}{|c|c|c|}
\hline Variables & Hazard ratio $(95 \% \mathrm{Cl})$ & $\mathrm{P}$ value \\
\hline CRC stage $(\mathrm{I}+\mathrm{II}+\mathrm{III}$ vs. IV) & $6.719(2.988-15.107)$ & $<0.001$ \\
\hline Lower level of lipocalin 2 [<116.7 (ng/ml)] & $5.251(2.233-12.346)$ & $<0.001$ \\
\hline CEA $(x 10 \mathrm{ng} / \mathrm{ml})^{*} \dagger$ & $1.006(1.001-1.012)$ & 0.029 \\
\hline
\end{tabular}

*Value was used as continuity

† Indicated increased each 1.001 Hazard ratio when CEA increased $10 \mathrm{ng} / \mathrm{m}$

$\mathrm{Cl}$ : Confidence Interval; CEA: Carcinoembryonic Antigen; CRC: Colorectal Cancer.

Table 5: Univariable Cox Regression Analysis of Predictors for CRC-Caused Death or CRC Distal Metastasis During Long-term Follow-up.

\begin{tabular}{|c|c|c|}
\hline Variables & Hazard ratio $(95 \% \mathrm{Cl})$ & $\mathrm{P}$ value \\
\hline CRC stage $(\mathrm{I}+\mathrm{II}+\mathrm{III}$ vs. IV) & $9.451(3.896-22.926)$ & $<0.001$ \\
\hline Lower level of lipocalin 2 [<116.7 $(\mathrm{ng} / \mathrm{ml})]$ & $8.033(3.160-20.419)$ & $<0.001$ \\
\hline
\end{tabular}

*Value was used as continuity.

$\dagger$ Indicated increased each 1.001 Hazard ratio when CEA increased $10 \mathrm{ng} / \mathrm{ml}$

$\mathrm{Cl}$ : Confidence Interval;

Table 6: Multivariable Stepwise Cox Regression Analysis of Predictors for Cancer Death or Cancer Distal Metastasis during Long-term Follow-up.

comparison with those with lower levels of lipocalin $2(<116.7 \mathrm{ng} / \mathrm{ml})$ (Figures $3 \mathrm{~A}$ and $3 \mathrm{~B}$ ).

\section{Discussion}

The present study, which examined the serum level of lipocalin 2 and clinically relevant variables in patients with CRC undergoing surgical intervention, has several clinical implications. First, circulating level of lipocalin 2 was significantly higher in study patients than in healthy control subjects. Second, the circulating level of lipocalin 2 was significantly lower in patients with stage IV CRC than in those patients with stages I, II and III CRC. Third, the lower circulating level of lipocalin $2(<116.7 \mathrm{ng} / \mathrm{ml})$ and stage IV CRC were the strongest independent predictors of combined primary endpoint (defined death from any cause or occurrence of new onset of metastasis) and combined secondary endpoint (defined as death caused by CRC or metastasis) during long-term follow up.

Surprisingly, despite the association between lipocalin 2 level and inflammatory colon disease and distal organ metastasis from lung, pancreas, ovarian and breast cancers being the subject of extensive investigation [25-30], the link between the circulating level of this biomarker and the prognostic outcomes in CRC patients has not been reported. To the best of our knowledge, this is the first study to investigate the impact of circulating level of lipocalin 2 on the long-term prognostic outcome in CRC patients undergoing surgical intervention. One important finding was that the circulating level of lipocalin 2 was remarkably higher in CRC patients than in healthy control subjects. This finding suggests that lipocalin 2 was not only increased in chronic inflammatory colon disease [31] but was also increased in CRC patients.

Unexpectedly, this study did not show a good correlation between circulating level of lipocalin 2 and the clinical stages of CRC (Figure 3A). Further analysis also showed no significant correlation between circulating level of lipocalin 2 and early CRC stages (i.e., combined stage I, II and III) and advanced CRC stage (i.e., stage IV). However, the ROC curve analysis showed that a higher circulating level of lipocalin $(2 \geq 116.7 \mathrm{ng} / \mathrm{ml})$ was strongly associated with favorable long-term clinical outcome. From this point of view, our finding is supported by a previous in vitro study which demonstrated that a higher level of NGAL (i.e., lipocalin 2) may be a candidate metastasis suppressor in colon cancer cells [20].

In addition, circulating level of CEA, an traditionally important index of recurrence of CRC in patients after receiving surgical and/or pharmacological interventions [8,32], was found to be independently predictive of primary combined endpoint (i.e., any cause of death or new onset of distal organ metastasis) during long-term follow up. This result reinforces the findings of previous studies [8,32]. However, our study showed that compared with CEA, lower circulating level of lipocalin 2 was more strongly and independently predictive of primary combined endpoint. Of particular importance is the fact that combined use of these two biomarkers (i.e., lipocalin and higher CEA level) was found superior to either one alone for prediction of primary combined endpoint. Our findings thus encourage the use of these two biomarkers together to stratify CRC patients into higher-risk and lower-risk subgroups during long-term follow-up in daily clinical practice.

(A)

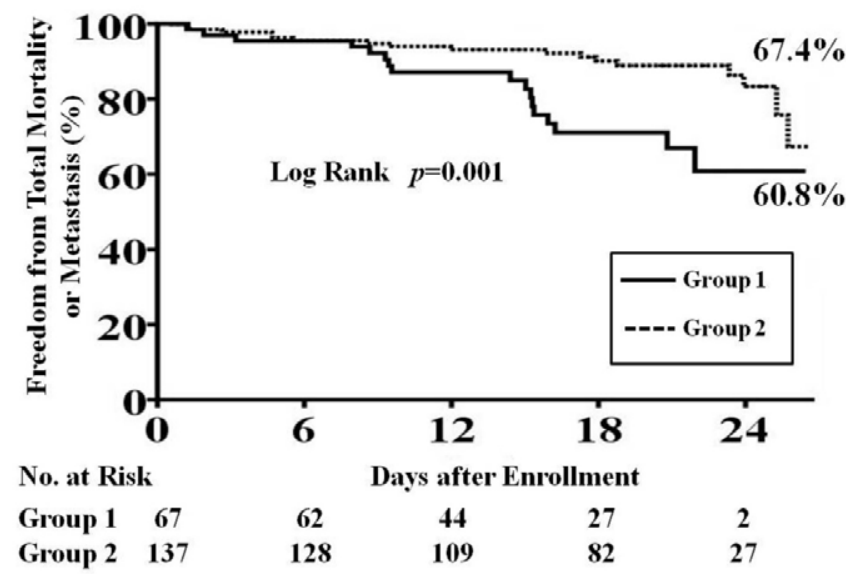

(B)

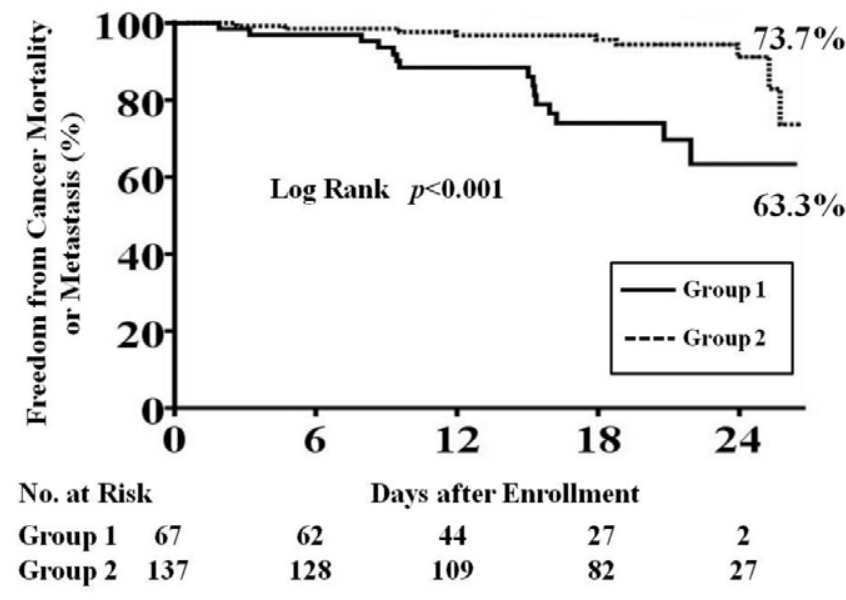

Figure 3: Kaplan Meyer analysis: (A) The Kaplan Meyer analysis comparing the survival rate between group 1 (i.e., lipocalin 2 levels $<116.7 \mathrm{ng} / \mathrm{ml}$ ) and group 2 (i.e., lipocalin 2 levels $\geq 116.7 \mathrm{ng} / \mathrm{ml}$ ) patients, demonstrating the long-term primary combined endpoint was notably higher in group 1 than in group 2 patients $(p=0.001)$. (B) The Kaplan Meyer analysis comparing the survival rate between group 1 (i.e., lipocalin 2 levels $<116.7 \mathrm{ng} / \mathrm{ml}$ ) and group 2 (i.e., lipocalin 2 levels $\geq 116.7 \mathrm{ng} / \mathrm{ml}$ ) patients, demonstrating the long-term secondary combined endpoint was notably higher in group 1 than in group 2 patients $(p<0.001)$. 
Citation: Chang CL, Chen YL, Chen YT, Leu S, Chang LT, et al. (2014) Lipocalin 2 Level Predicts Prognostic Outcome in Patients with Colorectal Cancer Undergoing Surgical Intervention. J Mol Biomark Diagn 5: 162. doi:10.4172/2155-9929.1000162

Page 6 of 7

Another principal finding was that the lower circulating level of lipocalin 2 was the strongest and most independent predictor of combined secondary endpoint (i.e., CRC-caused death or new occurrence of distal metastasis) during long-term follow up. Our findings thus provide evidence that lipocalin 2 is a useful biomarker for monitoring the long-term clinical status of CRC patients following surgical/pharmacological therapies. An extremely surprising finding was that in comparison with our result, previous studies have demonstrated that higher rather than lower levels of lipocalin 2 are significantly predictive of distal metastasis in lung, pancreas, ovarian and breast cancer settings [21-23,26, 27,31]. However our results are supported by one previous experimental study [20] that found that higher levels of lipocalin 2 suppressed the invasion and metastasis of colon cancer cells to the liver. We are uncertain why there is discrepancy between our and previous findings [21,22,26,27,31]. Perhaps different cancer cells (i.e., CRC vs. lung, ovarian, breast and pancreas cancer cells) have divergent responses to stimulation by different lipocalin 2 concentrations in invasion and mobilization, and distal organ metastasis.

It is well known that stage IV CRC, an advanced cancer stage, always indicates a poorer prognostic clinical outcome as compared with stages I, II and III of CRC $[28,29]$. Consistently, the findings of the present study also showed that the stage IV of CRC was independently predictive of primary and secondary combined endpoints during long-term clinical follow up. Our findings, therefore, strengthen the findings of previous studies $[28,29]$. Interestingly, WBC count was also an independent predictor of combined primary endpoint. Previous studies have demonstrated the association between neoplasm and inflammatory reaction $[30,33]$. These findings [30,33] may, at least in part, explain why WBC count was independently predictive of unfavorable clinical outcome in CRC patients.

\section{Study Limitations}

This study has several limitations. First, the sample size of this cohort study was relatively small. This may explain why the correlation between circulating level of lipocalin 2 and the clinical stages of CRC did not reach the statistical significance. Additionally, this may also explain why the sensitivity and specificity of ROC curve analysis were found to be relatively low in the current study. Second, the same reason could also be used to explain why mortality did not significantly differ in patients with higher lipocalin 2 level as compared with those patients with lower levels of this biomarker. Similarly, the incidence of unfavorable long-term clinical outcome (i.e., death from any cause or cancer metastasis) which was relatively low could, at least in part, explain why the sensitivity and specificity of ROC curve analysis were found to be relatively low in the present study. Third, Body Mass Index (BMI) is usually identified as a useful predictor of prognostic outcome in various types of cancers. In the current study, however, this parameter was missing. Therefore, we did not know whether the BMI was an important factor for predictive of prognostic outcome in CRC patients.

\section{Conclusion}

In conclusion, the results of our study demonstrated that lower circulating levels of lipocalin 2 were a strong and independent predictor of long-term unfavorable clinical outcome in CRC patients undergoing surgical/pharmacological and or irradiation intervention. This finding encourages the use of this biomarker as a supplementary parameter for use alongside CEA to monitor CRC patients in daily clinical practice.

\section{Acknowledgement}

This study was supported by a program grant from Chang Gung Memorial Hospital, Chang Gung University (Grant number: CMRPG8A0791).

\section{References}

1. Cunningham D, Atkin W, Lenz HJ, Lynch HT, Minsky B, et al. (2010) Colorectal cancer. Lancet 375: 1030-1047.

2. Ferlay J, Shin HR, Bray F, Forman D, Mathers C, et al. (2010) Estimates of worldwide burden of cancer in 2008: GLOBOCAN 2008. Int J Cancer 127: 2893-2917.

3. Jemal A, Bray F, Center MM, Ferlay J, Ward E, et al. (2011) Global cancer statistics. CA Cancer J Clin 61: 69-90

4. Fath RB Jr, Winawer SJ (1983) Early diagnosis of colorectal cancer. Annu Rev Med 34: 501-517.

5. Simmonds PC, Primrose JN, Colquitt JL, Garden OJ, Poston GJ, et al. (2006) Surgical resection of hepatic metastases from colorectal cancer: a systematic review of published studies. Br J Cancer 94: 982-999.

6. Le Voyer TE, Sigurdson ER, Hanlon AL, Mayer RJ, Macdonald JS, et al. (2003) Colon cancer survival is associated with increasing number of lymph nodes analyzed: a secondary survey of intergroup trial INT-0089. J Clin Oncol 21: 2912-2919.

7. Burt RW, Barthel JS, Dunn KB, David DS, Drelichman E, et al. (2010) NCCN clinical practice guidelines in oncology. Colorectal cancer screening. J Natl Compr Canc Netw 8: 8-61.

8. Desch CE, Benson AB 3rd, Somerfield MR, Flynn PJ, Krause C, et al. (2005) Colorectal cancer surveillance: 2005 update of an American Society of Clinical Oncology practice guideline. J Clin Oncol 23: 8512-8519.

9. He J, Efron JE (2011) Screening for colorectal cancer. Adv Surg 45: 31-44.

10. Walsh JM, Terdiman JP (2003) Colorectal cancer screening: scientific review. JAMA 289: 1288-1296.

11. Wilson JM, Jungner YG (1968) [Principles and practice of mass screening for disease]. Bol Oficina Sanit Panam 65: 281-393.

12. Triebel S, Bläser J, Reinke H, Tschesche H (1992) A 25 kDa alpha 2-microglobulin-related protein is a component of the $125 \mathrm{kDa}$ form of human gelatinase. FEBS Lett 314: 386-388.

13. Kjeldsen L, Johnsen AH, Sengeløv H, Borregaard N (1993) Isolation and primary structure of NGAL, a novel protein associated with human neutrophi gelatinase. J Biol Chem 268: 10425-10432.

14. Yang J, Goetz D, Li JY, Wang W, Mori K, et al. (2002) An iron delivery pathway mediated by a lipocalin. Mol Cell 10: 1045-1056.

15. Devireddy LR, Teodoro JG, Richard FA, Green MR (2001) Induction of apoptosis by a secreted lipocalin that is transcriptionally regulated by IL-3 deprivation. Science 293: 829-834.

16. Flo TH, Smith KD, Sato S, Rodriguez DJ, Holmes MA, et al. (2004) Lipocalin 2 mediates an innate immune response to bacterial infection by sequestrating iron. Nature 432: 917-921.

17. Goetz DH, Holmes MA, Borregaard N, Bluhm ME, Raymond KN, et al. (2002) The neutrophil lipocalin NGAL is a bacteriostatic agent that interferes with siderophore-mediated iron acquisition. Mol Cell 10: 1033-1043.

18. Cowland JB, Borregaard N (1997) Molecular characterization and pattern of tissue expression of the gene for neutrophil gelatinase-associated lipocalin from humans. Genomics 45: 17-23.

19. Friedl A, Stoesz SP, Buckley P, Gould MN (1999) Neutrophil gelatinaseassociated lipocalin in normal and neoplastic human tissues. Cell type-specific pattern of expression. Histochem J 31: 433-441.

20. Lee HJ, Lee EK, Lee KJ, Hong SW, Yoon Y, et al. (2006) Ectopic expression of neutrophil gelatinase-associated lipocalin suppresses the invasion and liver metastasis of colon cancer cells. Int J Cancer 118: 2490-2497.

21. Shi H, Gu Y, Yang J, Xu L, Mi W, et al. (2008) Lipocalin 2 promotes lung metastasis of murine breast cancer cells. J Exp Clin Cancer Res 27: 83

22. Cho H, Kim JH (2009) Lipocalin2 expressions correlate significantly with tumor differentiation in epithelial ovarian cancer. J Histochem Cytochem 57: 513-521.

23. Bauer M, Eickhoff JC, Gould MN, Mundhenke C, Maass N, et al. (2008) 
Citation: Chang CL, Chen YL, Chen YT, Leu S, Chang LT, et al. (2014) Lipocalin 2 Level Predicts Prognostic Outcome in Patients with Colorectal Cancer Undergoing Surgical Intervention. J Mol Biomark Diagn 5: 162. doi:10.4172/2155-9929.1000162

Neutrophil gelatinase-associated lipocalin (NGAL) is a predictor of poor prognosis in human primary breast cancer. Breast Cancer Res Treat 108: 389397.

24. Hu L, Hittelman W, Lu T, Ji P, Arlinghaus R, et al. (2009) NGAL decreases E-cadherin-mediated cell-cell adhesion and increases cell motility and invasion through Rac1 in colon carcinoma cells. Lab Invest 89: 531-548.

25. Edge SB, Compton CC (2010) The American Joint Committee on Cancer: the 7 th edition of the AJCC cancer staging manual and the future of TNM. Ann Surg Oncol 17: 1471-1474.

26. Rodvold JJ, Mahadevan NR, Zanetti M (2012) Lipocalin 2 in cancer: when good immunity goes bad. Cancer Lett 316: 132-138.

27. Tong Z, Kunnumakkara AB, Wang H, Matsuo $Y$, Diagaradjane $P$, et al. (2008) Neutrophil gelatinase-associated lipocalin: a novel suppressor of invasion and angiogenesis in pancreatic cancer. Cancer Res 68: 6100-6108.

28. Fong Y, Fortner J, Sun RL, Brennan MF, Blumgart LH (1999) Clinical score for predicting recurrence after hepatic resection for metastatic colorectal cancer: analysis of 1001 consecutive cases. Ann Surg 230: 309-318.

29. Gunderson LL, Jessup JM, Sargent DJ, Greene FL, Stewart AK (2010) Revised TN categorization for colon cancer based on national survival outcomes data. J Clin Oncol 28: 264-271.

30. Coussens LM, Werb Z (2002) Inflammation and cancer. Nature 420: 860-867.

31. Nielsen BS, Borregaard N, Bundgaard JR, Timshel S, Sehested M, et al. (1996) Induction of NGAL synthesis in epithelial cells of human colorectal neoplasia and inflammatory bowel diseases. Gut 38: 414-420.

32. Engstrom PF, Arnoletti JP, Benson AB 3rd, Chen YJ, Choti MA, et al. (2009) NCCN Clinical Practice Guidelines in Oncology: colon cancer. J Natl Compr Canc Netw 7: 778-831.

33. Balkwill F, Mantovani A (2001) Inflammation and cancer: back to Virchow? Lancet 357: 539-545. 